\title{
Call for Papers
}

Dear Authors,

A special issue of MASA Volume 4 (2009) No 3 would be devoted to the Statistics in Marketing \& Advertising Research. The papers should be received up to March 31st, 2009.

Another special issue of MASA Volume 4 (2009) No 4 would consider the teaching statistics problems. The papers should be received up to June 30th, 2009.

And send your works after the deadlines too - they can enter into the next issues.

If you wish, propose any special topics to consider in the journal as well.

Guest Editor for MASA 2009,

Dr. Stan Lipovetsky

Senior Research Director

GfK Custom Research North America

Marketing Science

Research Center for Excellence

8401 Golden Valley Road

Minneapolis, MN 55427, USA

Phone +1 763-417-4509

Fax +1 763-542-0864

stan.lipovetsky@gfk.com

www.gfkamerica.com 